\title{
Special Issue on International Nonthermal Food Processing Workshop: Florianópolis 2013
}

\author{
Amauri Rosenthal ${ }^{1}$
}

Published online: 11 June 2015

(C) Springer Science+Business Media New York 2015

The second part of this Special Issue is based on presentations at the Nonthermal Food Processing Workshop held in Florianópolis, Santa Catarina, Brazil, October 1-2, 2013. This time the theme of the Workshop was "Research and Innovation Towards Competitiveness" and the hosts were EMBRAPA (Brazilian Agricultural Research Corporation) and SENAI (Brazilian National Service of Industrial Apprenticeship). The Workshop is an annual event organized by the Nonthermal Processing Division of the Institute of Food Technologists (IFT) and the European Federation of Food Science and Technology (EFFoST) in a number of countries from around the world.

This event gathered some of the most recognized experts on nonthermal processing of food presenting the most recent scientific and technological advances in the field. There were 260 delegates from 14 countries, where $47 \%$ were from research institutes, $38 \%$ from academic institutions and $15 \%$ from industry. The workshop was organized around four topics as follows: (1) Food safety and legislation; (2) Marketing, competitiveness and innovation, (3) Nutritional and sensory quality and (4) Sustainability in the food industry, emphasizing energy savings, water usage, waste and by-products. These topics were addressed by 20 invited speakers together with 11 more oral presentations and 150 posters.
A good number of nonthermal technologies were presented and discussed during these very comprehensive and intense 2 days. In addition to the presentations, either oral or poster, there were breakout sessions to identify future steps toward commercialization of some of the technologies addressed during the workshop. Some of them were: pulsed electric fields (PEF), high-pressure processing (HPP), cold plasma, ultrasound, ultraviolet, pulsed light, ozone, membrane technology, irradiation, active packaging and extraction, dense-phase carbon dioxide.

The articles included in this second part of this FERE Special Issue are based on the best presentations at the workshop. All submitted manuscripts were peer-reviewed following the journal standards, and as a result of this process, thirteen of them are included. All are research articles, even though the journal only publishes review articles. This was a special concession by Springer and FERE Editors. These articles are covering different aspects of high-pressure processing, membrane technology, osmotic dehydration, ultrasound extraction, irradiation, to name a few.

It is very much expected these articles, which are the results of an excellent event, will be useful contributions to develop further the ever-expanding field of nonthermal processing of food.

Amauri Rosenthal

amauri.rosenthal@embrapa.br

1 EMBRAPA Food Technology, Av. das Americas 29501, Rio de Janeiro, RJ 23020-470, Brazil 